\title{
PERCEPÇÕES DE ESTUDANTES E PROFISSIONAIS CHINESES SOBRE O STATUS DO INGLÊS COMO LÍNGUA FRANCA ${ }^{1}$
}

\author{
Luciana Cabrini Simões CALVO - UEM/ PPG-UEL \\ Eliane Segatti RIOS-REGISTRO - UENP/CP - PPG-UEL \\ Márcia Cristina Greco OHUSCHI - UEM / PPG-UEL \\ Michele Salles EL KADRI - PPG-UEL / CAPES
}

\section{Resumo}

A expansão do uso da língua inglesa caracterizou-a como língua franca global. Em decorrência, esse status trouxe a necessidade de reconceitualizações do que seja ensinar essa língua, seus objetivos e seus modelos. Assim, neste estudo, objetivamos investigar quais são as percepções de dez profissionais e estudantes chineses sobre o status da língua inglesa como língua franca. O referencial teórico apóia-se em Phillipson (2008), Mckay (2003), Pennycook (1994), Leffa (2002) e Gimenez (2002; no prelo). Como instrumento de coleta de dados, utilizamos um questionário com perguntas abertas, respondidas pelos participantes da pesquisa. Do que foi analisado, concluímos que a visão dos sujeitos entrevistados se aproxima da visão dos pesquisadores sobre o status dessa língua: ao considerarem relevante sua aprendizagem para propósitos específicos; ao valorizarem a cultura do próprio país e não apenas daqueles que a possuem como primeira língua; ao considerá-la útil para a comunicação com pessoas de vários lugares do mundo. Por outro lado, os chineses pesquisados preferem como professor o falante nativo, divergindo, assim, da opinião dos estudiosos.

Palavras-chave: Ensino de língua inglesa. Língua franca. Inglês na China.

\begin{abstract}
The expansion of the English language characterized it as a global franca language. As a result, this status brought the need of new concepts of what it is to teach this language, its objectives and its models. Thus, in this study, we aim to investigate the perceptions of ten Chinese students and professionals concerning the status of the English language as a lingua franca. Theoretical assumptions are drawn from Phillipson (2008), Mckay (2003), Pennycook (1994), Leffa (2002) and Gimenez (2002; forthcoming). This research was carried out through the administration of a questionnaire with open questions, answered by the participants. Data show that the Chinese seem to recognize the status of the English as a lingua franca because: they consider its learning for specific purposes; they do not privilege the native speaker's culture; they claim that the English language is a language used for
\end{abstract}

\footnotetext{
${ }^{1}$ Este estudo é parte de uma pesquisa maior, realizada durante a disciplina "O ensino de língua estrangeira na contemporaneidade", ministrada pela professora doutora Telma Gimenez, do Programa de Pós-Graduação em Estudos da Linguagem da Universidade Estadual de Londrina.
} 
communication with other non-native speakers. However, they still prefer the native teacher as the model to be followed.

Keywords: English teaching. Lingua franca. English in China.

\section{Introdução}

A língua inglesa atingiu uma grande dimensão na sociedade moderna, pois, no contexto da globalização, conforme Seidlhofer (2001), passou a ser utilizada internacionalmente como meio de comunicação, principalmente entre falantes não-nativos, o que a caracterizou como uma língua internacional ou uma língua franca ${ }^{2}$. Língua franca, de acordo com Seidlhofer (2001, p. 146), é definida como

um sistema linguístico adicional que serve como meio de comunicação entre falantes de diferentes línguas maternas, ou uma língua que os membros de diferentes comunidades discursivas podem se comunicar uns com os outros, mas que não é a língua materna de nenhum deles - uma língua que não tem falantes nativos ${ }^{3}$.

O fato de pensar e considerar o inglês como uma língua franca traz muitas especulações, desafios e expectativas para todos os usuários dessa língua, e mais especificamente, para aqueles envolvidos no seu ensino. Dessa forma, pretendemos, com este artigo, analisar as percepções de dez profissionais e estudantes chineses sobre o status da língua inglesa como língua franca.

Com esse propósito, a partir da Linguística Aplicada, a pesquisa se caracteriza como qualitativo-interpretativa, de natureza aplicada, embasada nos pressupostos teóricos de Phillipson (2008), Mckay (2003), Pennycook (1994), e de pesquisadores que seguem esta vertente, como Gimenez (2002, prelo) e Leffa (2002). Para coletar os registros, utilizamos um questionário, com perguntas abertas.

\footnotetext{
${ }^{2}$ Preferimos utilizar nesta pesquisa o termo inglês como língua franca (doravante ILF) por concordarmos com Seidlhofer (2001), a qual expõe que o termo 'internacional' falha ao levar em consideração somente os falantes do círculo interno e do círculo externo e com Jenkins (2006) quando ressalta que o termo 'língua internacional' tem sido usado para se referir a diferentes conceitos que pode levar a confusões terminológicas.

${ }^{3}$ an additionally acquired language system that serves as a means of communication between speakers of different first languages, or a language by means of which the members of different speech communities can communicate with each other but which is not the native language of either - a language which has no native speakers.
} 
Assim, aqui é feita a exposição de algumas considerações teóricas sobre o inglês como língua franca e as implicações pedagógicas para seu ensino. $\mathrm{Na}$ sequência, traçamos um percurso histórico do inglês na China, seguido pela explanação a respeito da pesquisa e dos sujeitos, além da análise dos dados. Por fim, apresentamos algumas considerações finais sobre o trabalho.

\section{Inglês como língua franca: concepções desse novo status e reflexões sobre o seu ensino}

Nesta seção, discutimos sobre as diferentes concepções a respeito da expansão da língua inglesa, bem como sobre a definição do termo "língua franca" e os diferentes discursos que circulam sobre esta perspectiva. Além disso, apresentamos algumas implicações pedagógicas para o ensino de inglês como língua franca, tais como a descentralização do falante-nativo; o não-privilégio apenas da cultura de países que tem a língua inglesa como primeira língua; questões relacionadas à pronúncia e ao ensino gramatical.

\subsection{Algumas considerações sobre o inglês como língua franca}

A globalização traz a necessidade de uma língua comum no mundo, que funcione como língua franca, pelo fato de possibilitar a compreensão mútua e garantir o acesso a diferentes fontes de informação. Corroborando essa ideia, Leffa (2002) também afirma que a globalização pede uma língua multinacional para propósitos específicos.

Conforme Leffa (2002), para uma língua ser considerada franca ou multinacional (terminologia usada por ele), ela deve ir ao encontro de três critérios: 1) não ter falantes nativos, ou seja, todos devem usá-la como língua estrangeira; 2) ser independente de uma cultura, isto é, diferentes países devem usá-la; 3) ser usada apenas para propósitos específicos.

O referido autor evidencia não existir uma língua natural que apresente esses critérios, mas salienta o fato de o inglês ser a língua que mais se aproxima deles, principalmente por haver mais falantes não-nativos do que nativos da língua: para cada falante nativo, há três falantes não-nativos de inglês.

McKay (2003), por sua vez, argumenta que o inglês alcançou este status de língua franca devido ao aumento no número de indivíduos que acreditam ser um benefício aprender a língua inglesa como uma língua adicional. Segundo esta autora, o crescente número de pessoas no mundo que tem uma familiaridade com o inglês permite que essa língua atue como 
uma língua para comunicação mais ampla com diferentes propósitos, contribuindo para seu status de língua franca global. Ainda de acordo com McKay (2003, p. 2), "no processo de adquirir esse status, a natureza do inglês mudou em termos de quantos falantes fazem uso dessa língua e como o inglês se relaciona com cultura"4.

Diante desse novo status da língua inglesa, estudos (SEIDLHOFER, 2001; JENKINS, 2000) apontam que há cada vez mais pesquisadores interessados e dedicados ao estudo do ensino de inglês como língua franca. No entanto, como apresentaremos em seguida, essa reconsideração de tal status ainda é uma questão polêmica que suscita desconfiança pelo fato de desafiar pressupostos do ensino de inglês como língua estrangeira, tradicionalmente considerados únicos e verdadeiros.

Phillipson (2008), por exemplo, defende que rotular o inglês como língua franca normalmente entendido como um meio neutro de comunicação que posiciona todos os falantes de maneira igualitária - é totalmente falso pelo fato dessa perspectiva eliminar a diversidade linguística. Para esse autor, as políticas linguísticas que privilegiam o ensino de inglês como língua franca estão promovendo a destruição das outras línguas, favorecendo o que ele denomina de "linguicídio" (p. 251).

Pennycook (1994), em seu turno, evidencia que, a disseminação do inglês é considerada por muitos como natural, neutra e benéfica. No entanto, esse autor se posiciona contrariamente a essa ideia. Pennycook (1994) argumenta que considerar a disseminação da língua inglesa como natural significa ignorar a história da sua disseminação, forças globais maiores, objetivos e interesses de instituições e governos que promoveram esse status. Ainda de acordo com o mencionado autor, considerar essa expansão como neutra, é tomar uma visão bastante particular de língua e também assumir que o status internacional do inglês seja superior às preocupações locais, culturais, políticas ou econômicas. Por fim, o autor salienta que considerar essa disseminação benéfica é assumir uma posição otimista inocente sobre relações globais e ignorar as relações entre o inglês e as distribuições desiguais e fluxos de riquezas, recursos, cultura e conhecimento (PENNYCOOK, 1994).

Como vimos, há diferentes estudiosos que concebem o inglês como língua franca de forma positiva e favorável, no entanto, há outros que apresentam ressalvas quanto a esse status. Desse modo, concluímos que ainda há muito a ser discutido acerca da problematização do inglês como língua franca, especificamente no que se refere ao ensino da língua inglesa

\footnotetext{
${ }^{4}$ In the process of achieving this status, the very nature of English has changed in terms of how many of its speakers make use of English and how English relates to culture.
} 
nesse cenário. Dessa forma, discutimos, em seguida, as implicações pedagógicas para o seu ensino.

\subsection{Implicações pedagógicas para o ensino de inglês como língua franca}

Como vimos anteriormente, considerar o inglês como língua franca significa também reconsiderar o seu ensino, desafiando as noções tradicionais que sustentam o inglês como língua estrangeira, principalmente sua vinculação com falantes nativos dessa língua.

Desse modo, se concebermos o inglês como língua franca, devemos levar em consideração alguns fatores que têm certas implicações no ensino dessa língua, tais como: a) o falante nativo não é mais o modelo a ser seguido; b) não há mais por que ensinar a cultura exclusiva de países do círculo interno ${ }^{5}$ (já que o inglês não pertence a nenhum país em específico); c) é necessário uma reconsideração sobre pronúncia e gramática em sala de aula.

A primeira dessas implicações, conforme indicada acima, é a descentralização do falante nativo como modelo a ser seguido. Essa implicação é explicada pelo fato de que, se considerarmos que a maioria dos encontros internacionais é entre falantes não-nativos da língua inglesa, não há porque manter o falante nativo como referencial. Para a sala de aula, isso traria a necessidade de valorização de diferentes variedades do inglês, oriundas tanto do círculo interno, quanto do círculo externo e também do círculo em expansão. O importante para essa perspectiva seria, portanto, garantir a inteligibilidade entre os falantes.

Outra implicação seria a respeito do ensino de cultura. No ensino de inglês como língua estrangeira, a cultura privilegiada é a do país do falante nativo, especialmente do círculo interno, e mais especificamente da Inglaterra e dos Estados Unidos. Gimenez (2002; no prelo) relembra que, nos encontros interculturais, a pessoa não precisa conhecer a cultura do outro para poder interagir. Assim, para o ensino de inglês como língua franca, o essencial seria desenvolver a chamada competência intercultural, ou seja, a capacidade de lidar com uma situação em que não ocorra a compreensão esperada na comunicação:

\footnotetext{
${ }^{5}$ De acordo com Kachru (1985 apud KACHRU; KACHRU; NELSON, 2006), o círculo interno refere-se aos países onde o inglês é usado como língua materna (exemplos: Reino Unido, Estados Unidos, Nova Zelândia, Austrália e Canadá); o círculo externo refere-se a contextos pós-coloniais anglofônicos e que usam o inglês como uma de suas línguas (exemplo: Índia, Nigéria, Singapura); o círculo em expansão refere-se a países que usam a língua inglesa como língua estrangeira (exemplo: China, Rússia, Japão, Brasil).
} 
um falante interculturalmente competente seria aquele que opera sua competência lingüística e sua conscientização sociolingüística a respeito da relação entre língua e o contexto onde é usada, a fim de interagir ao longo das fronteiras culturais, prever mal-entendidos, decorrentes de diferenças em valores, significados e crenças, e, finalmente, para lidar com as demandas cognitivas e afetivas do engajamento com o outro (LIDDICOAT \& CROZET, 1999 apud GIMENEZ, 2002, p. 113).

A mudança na língua relacionada à pronúncia, particularmente, é tratada por Jenkins (2000). Ao pesquisar interações de inglês como língua franca, a mencionada autora sugere um modelo fonológico denominado Lingua Franca Core, o qual apresenta aspectos da pronúncia considerados importantes para se manter a inteligibilidade nas interações entre os diversos falantes da língua.

Sobre as implicações da pronúncia em sala de aula, podemos afirmar que o professor pode privilegiar a prática de sons necessários para a inteligibilidade, ou seja, se a pronúncia do aluno não impedir a comunicação entre outros falantes não-nativos, ele não deveria ser corrigido.

Quanto ao ensino gramatical, o projeto $\mathrm{VOICE}^{6}$ organizado por um grupo de pesquisadores da Universidade de Viena, embora sem aspirações didáticas, fornece um corpus de inglês oriundo de falantes não-nativos em diferentes contextos, trazendo implicações para a sala de aula. Nesse projeto, os pesquisadores demonstram as principais mudanças na língua, utilizadas por esses falantes, que não impedem a comunicação. ${ }^{7}$

Jenkins (2006, p. 170) nos oferece alguns exemplos dessas mudanças:

- o não-uso da terceira pessoa do singular no presente simples - "s" (Ex: She look very sad);

- o uso intercambiável dos pronomes relativos 'who' e 'which' (Ex: 'a book who, a person which)

- uso de 'isn't it' ou 'no' para todos os casos de 'tag questions' ao invés de “'shouldn't they' (They should arrive soon, isn't it).

- plural de substantivos que são considerados incontáveis no inglês do falante nativo (Ex. informations, staffs, advices)

6 Vienna-Oxford International Corpus of English, coordenado por Bárbara Seidlhofer. Disponível em: http://voice.univie.ac.at. Acesso em: 7 jul. 2009.

${ }^{7}$ Isso não significa, como apontam muitos céticos, que não se ensine mais gramática em sala de aula. 
A esse respeito, Gimenez (no prelo) ressalva que não se trata de permitir quaisquer erros em sala de aula, mas sim de haver maior flexibilização sobre o que considerar como erro. Para a autora, isso resultaria na eficácia do aprendizado do ponto de vista comunicativo.

Leffa (2002) também contribui para a discussão das implicações pedagógicas do ensino de uma língua considerada por ele multinacional, ou franca, conforme terminologia usada neste texto. Para ele, esse novo status da língua inglesa demanda um novo paradigma de ensino, envolvendo novas prioridades. Dentre elas, o referido autor cita as seguintes: a) considerar as variedades locais do inglês; b) desenvolver tolerância para as diferenças; c) ensinar inglês para produção; d) ensinar inglês para propósitos específicos.

No que diz respeito à consideração das variedades locais do inglês, Leffa (2002) salienta que se ensinamos inglês no Brasil, por exemplo, devemos aceitar o inglês brasileiro (Brazilian English) como uma das variedades legítimas do inglês. Assim, segundo ele, uma das condições para o inglês ser uma língua multinacional é o fato de aceitar a diversidade, incluindo a língua inglesa em si.

Sobre desenvolver tolerância para as diferenças, Leffa (2002) é da opinião de que não devemos ensinar aos nossos alunos a odiar outras culturas, ou a admirar culturas dominantes de maneira acrítica. No entanto, devemos conscientizar os alunos de que não existem culturas superiores ou inferiores, melhores ou piores; mas sim que elas são diferentes. Assim, de acordo com o autor, os alunos não deveriam ser privados da oportunidade de experimentar diferenças e aprender a aceitá-las.

Com relação ao ensino de inglês para produção, o autor acredita que é dever dos professores de inglês ajudar os alunos não apenas a importar informações, mas também a exportá-las. Essa visão que muda os alunos de consumidores para produtores de informação, de acordo com Leffa (2002), deve ser implementada e envolve as seguintes estratégias: 1) explorar notícias sobre o país do aluno, publicadas na mídia internacional, não somente para propósitos motivacionais, mas também para fornecer aos alunos substrato linguístico necessário para a produção; 2) ajudar os alunos a explicar sua própria cultura para outras pessoas; 3) explorar os interesses dos alunos, para que assim possam aprender como transformar a língua em um instrumento para ventilar suas ideias.

Com referência ao ensino de inglês para propósitos específicos, Leffa (2002) salienta que, em contextos de ensino de inglês como línguas estrangeiras, nós raramente usamos a língua para conversar com nossa(o) esposa(o) ou filhos. Nós a usamos profissionalmente ou 
academicamente. Assim, os alunos aprendem uma língua estrangeira para cumprir diferentes funções daquelas que eles precisam quando usam a língua materna.

Em suma, nessa concepção, o fato de o falante nativo não ser mais o modelo a ser seguido, de não haver mais um motivo para se ensinar apenas a cultura dos países do círculo interno, de se considerar a pronúncia inteligível em sala de aula e de se recontextualizar o ensino gramatical implica em uma ressignificação dos objetivos de ensino desta língua, que precisará estar aberta a novas possibilidades de ensinar e de aprender em função das necessidades exigidas pelo contexto atual.

Assim, após essas reflexões sobre o inglês como língua franca e suas implicações em situação de ensino, passamos para uma breve apresentação de como a China inseriu a língua inglesa em seu contexto político e educacional.

\section{A língua inglesa no cenário chinês}

\subsection{Um pouco de história}

A China é o país mais populoso do mundo, com 1.3 bilhões de habitantes, e o que nos chama atenção, além do elevado número de chineses, é também a sua história. Em um breve percurso histórico, podemos comprovar que, segundo He (2005), desde 221 B.C, a China foi governada por 11 dinastias diferentes, refletindo uma nação controlada e unificada. A República da China foi estabelecida em 1911, dando fim a 2.000 anos de feudalismo. A partir de 1949, com a República Popular da China, o país ficou isolado do mundo por cerca de 30 anos.

Como assevera He (2005), somente no final da década de 70 o cenário mundial da China teve seu percurso alterado, quando o país, finalmente, adotou uma política de abertura ao mercado internacional (Open-Door Policy) e progrediu rumo à modernização, um resultado direto da necessidade para o avanço econômico do país. Finalmente, em 2001, a China uniu-se à Organização Mundial do Comércio, caracterizando um marco para o desenvolvimento do país no século XXI.

Diante disso, acreditamos que esse percurso histórico acaba por refletir vários fatores constitutivos da inserção da língua inglesa na China, portanto, elencamos a seguir alguns elementos que, a nosso ver, são marcas essenciais desse processo.

\subsection{O ensino da língua inglesa na China}


Ao longo dos anos, várias razões justificaram a aprendizagem da língua inglesa no cenário da China. Cowan et al. (1979) assevera que os chineses visualizam a língua inglesa como uma ferramenta com dois fins específicos: primeiro, para facilitar o acesso aos avanços científicos e tecnológicos; segundo, como um veículo para promover o comércio e também o diálogo entre a República da China e os outros países onde a língua inglesa seja primordial.

Diante disso, várias mudanças ocorreram, resultando em uma visão mais positiva da China sobre o ensino da língua inglesa nos últimos tempos. Esse ensino, conforme He (2005), entrou no currículo escolar no começo do século XX e, desde então, passou por altos e baixos devido às mudanças sóciopolíticas no país.

Segundo o autor, antes da Nova China (1902-1949), a língua inglesa chegou aos chineses com a tecnologia ocidental no final do século XIX, o que se pode observar através de algumas ações: a) jovens foram enviados ao exterior para aprender sobre ciência e tecnologia; b) textos importantes em inglês foram traduzidos para o chinês (como por exemplo, "A origem das espécies", de Charles Darwin); c) matérias estrangeiras foram introduzidas no sistema de exames das universidades; d) o inglês transformou-se numa ferramenta de acesso a essas informações; e) um número crescente de missionários britânicos e americanos chegou à China para pregar o Cristianismo, ajudando na difusão do inglês no país, principalmente nas classes sociais mais baixas.

A língua inglesa entrou no currículo escolar secundário junto com o alemão e o japonês em 1902. Depois de 10 anos, ela se tornou parte do currículo primário. Nove anos mais tarde, já na década de 1920, o inglês foi recomendado como a língua estrangeira principal nas escolas secundárias (HE, 2005).

Após esse período, em 1949, temos um marco para a história desse país. A República da China se estabeleceu e o ensino de língua inglesa, de acordo com He (op. cit.), caiu para o outro final do pêndulo, pois os ideais educacionais dos Estados Unidos e da Inglaterra eram vistos como não patriotas. O lugar do inglês no currículo escolar foi substituído pelo russo e, em 1954, o russo se tornou a única língua estrangeira ensinada nas escolas.

Como menciona He (2005), em 1953, sete de oito departamentos de língua inglesa nas universidades foram fechados e, em 1954, o ensino de línguas estrangeiras nas escolas primárias foi abolido e a língua russa se tornou a língua estrangeira principal para o nível secundário. 
Contudo, para Price (1971), entre o final da década de 50 e início da década de 60, a necessidade de abertura do país para o cenário internacional se tornou urgente, e com isso, a retomada da língua inglesa passou a ser muito significativa.

A partir de 1966, a China atravessa novas mudanças que surgiram durante o momento da chamada Revolução $\mathrm{Cultural}^{8}$, a qual perdurou até 1976. Nesse período, o ensino da língua inglesa foi bastante atingido, as escolas foram fechadas entre 1966-1968 e as universidades até 1971. Tudo que era estrangeiro, a exemplo de livros, filmes, músicas, etc, foi considerado burguês e proibido (HE, 2005).

Ainda nesse contexto, de acordo com o referido autor, em algumas escolas, as aulas de inglês tinham o objetivo de preparar os alunos para possíveis guerras contra a antiga União Soviética e inimigos da China no mundo ocidental. O foco do ensino foi exclusivamente em temas de propaganda política.

Um novo momento instaura-se na China com a política do Open-Door (1976atualmente), quando a China finalmente abre as suas portas para o oeste depois de 30 anos de isolamento. Isso aconteceu, de acordo com He (2005), como resultado direto da necessidade urgente para avanço econômico do país.

Com a abertura do país ao mercado internacional, mudanças importantes ocorreram no ensino de língua inglesa na China. Tal fato é justificado, primeiro, porque a modernização envolve atualização constante de banco de dados, e isto é feito principalmente através do inglês; segundo, pois com a entrada do país na Organização Mundial do Comércio, o inglês não é mais visto simplesmente como uma matéria no currículo escolar, mas como um instrumento para o trabalho e para a comunicação diária.

Diante desse quadro e em resposta às necessidades da reforma econômica nacional, novos objetivos foram formulados, principalmente no que diz respeito à educação, com uma orientação voltada à modernização, ao mundo exterior e ao futuro. O ensino da língua inglesa recebeu muito mais atenção em tal contexto e o resultado foi a produção de uma série de ementas e diretrizes para o seu ensino, emitidas para as instituições primárias, secundárias e terciárias.

De acordo com Fong (2009), em 2001, o governo lançou uma nova campanha em que as escolas primárias do país ofereceriam programas em inglês para alunos a partir do $3^{\circ}$ ano, com o objetivo de desenvolver neles interesse, confiança e atitude positiva em relação à

8 Como informação complementar sobre o impacto da Revolução Cultural na China, sugerimos a leitura da entrevista da chinesa Xiran Xue (2009), realizada por Oyama e publicada na revista Veja (19/07/2009). 
aprendizagem da língua. Para apoiar a implementação do novo currículo, livros foram publicados e cursos de desenvolvimento profissional foram oferecidos.

He (2005) postula que um problema sério a se destacar para a implementação das políticas governamentais é resultante da grande diversidade geográfica da China. No passado, a Comissão Educacional do Estado era responsável pelo desenvolvimento do currículo. Escolas e instituições terciárias tinham que implementá-lo com o mesmo rigor, entretanto, isso não acontecia na realidade.

Recentemente, o governo tem feito um esforço para lidar com esse problema através da introdução do currículo mínimo nos níveis primário e secundário. Sob essa política, governos locais podem tomar decisões sobre os objetivos da aprendizagem, a carga horária de ensino e os livros utilizados, de acordo com as necessidades e recursos de cada região.

À luz dessa política, grandes cidades como Pequim, Shanghai e Guangzhou projetaram seus próprios currículos com padrões mais elevados e com critérios mais rígidos do que aqueles do currículo nacional. Ainda, seus próprios materiais de ensino foram produzidos através da cooperação de editoras como a Oxford University Press e a Pearson Longman English Language Teaching. Isso indica, segundo He (2005), que a política governamental de entregar o controle central aos governos locais pode beneficiar somente regiões com força política e econômica.

Após esse breve percurso sobre a história do ensino da língua inglesa na China, passaremos a comentar um fato histórico que reflete diretamente o pensamento dos chineses sobre a língua inglesa: as Olimpíadas de Pequim.

\subsection{O Inglês na China com os preparativos para as Olimpíadas de Pequim}

A partir de 2001, quando ficou estabelecido que a China seria a sede para os jogos olímpicos de 2008, o mundo passou a acompanhar sete anos de preparação para um evento que oportunizaria aos chineses o "abrir das portas" de seu país ao mundo, mostrando sua história e seu passado glorioso (FONG, 2009).

Fong (op. cit.) ressalta que os chineses, nessa época, promoveram eventos que passaram a ser realizados anualmente, como por exemplo $A$ foreign language week e Beijing foreign language festival. Apresentações locais em inglês aconteciam semanalmente, em que as pessoas podiam se inscrever para aprender ou ensinar inglês como voluntários. Competições integrando as famílias e as escolas, promovendo debates de temas para os 
adultos e de vocabulário para as crianças também aconteciam regularmente, pois para os chineses, as atividades culturais eram parte constitutiva de sua formação.

Outro exemplo (FONG, 2009) é o Beijing foreign language community of excellence, evento em que o governo incentivava com premiações as localidades que mais se empenhavam no aprendizado da língua inglesa.

Conforme o autor, o governo chinês fez doações, para as escolas públicas, de materiais para a aprendizagem da língua. Manuais, panfletos e materiais também foram distribuídos a policiais, restaurantes e motoristas de táxi. Houve, ainda, a preocupação de informar os nomes de rodovias, placas e cardápios de restaurantes também em inglês.

Todos esses exemplos nos fazem refletir sobre o quanto essa preparação para os jogos olímpicos influenciou não somente o aspecto cultural e pessoal dos chineses, como também afetou diretamente a política de desenvolvimento do país.

\subsection{A China hoje}

Vance (2008) assevera que, nos dias atuais, para que um chinês seja bem sucedido, não basta saber a língua inglesa, ele deve ser fluente nela. Como resultado dessa postura, além de escolas e universidades que oferecem o ensino da língua inglesa, há também milhares de centros de treinamento que objetivam especializar tanto adultos quanto crianças nessa língua.

Segundo o professor Zhang Lianzhod $(2007)^{9}$, do Ministério da Educação da China, dos 224 milhões de alunos de seu país, 200 milhões estão estudando inglês. Para ele, o domínio do idioma é considerado elemento chave para a política de abertura do país ao mercado internacional.

O referido professor afirmou que, segundo previsões de especialistas, a China deve se tornar a primeira economia mundial em 2050. Para ele,

(a) idéia é substituir os produtos "made in China" por produtos "designed in China", explicou. Para dar este salto, o governo iniciou em 1999 o desenvolvimento de uma reforma educacional para alçar o ensino de inglês entre suas prioridades. "Por que estudar inglês? Para entender outras culturas, "abrir a cabeça", ultrapassar as barreiras de comunicação e aumentar a força intelectual do país" (PORTAL FAROL BRASIL, 2007).

\footnotetext{
${ }^{9}$ Citado no sítio do Portal Farol Brasil, 2007.
} 
Assim, podemos evidenciar, a partir dessa declaração, que a preocupação dos chineses não se restringe à mão-de-obra para a fabricação dos produtos, mas observamos também que eles se preocupam em pensá-los, desenhá-los e elaborá-los. A língua inglesa, ao que parece, é de fundamental importância nesse contexto, pois, através dela, não só produtos chineses podem ser conhecidos mundialmente, mas os chineses também podem ser vistos como seres pensantes de alta qualidade.

Por fim, concluímos que, atualmente, a China está voltada para uma educação visando a valorização de seu país, de sua cultura e de seu povo, fazendo uso da língua inglesa para atingir tais objetivos.

Na próxima seção, apresentaremos os dados e a análise referente ao questionário dos profissionais chineses participantes desta pesquisa.

\section{Dados sobre a pesquisa e sobre os sujeitos}

A presente pesquisa é de cunho qualitativo, situada dentro do paradigma interpretativista, pois tem como compromisso "a interpretação das ações sociais e o significado que as pessoas conferem a essas ações na vida social" (ERICKSON, 1990 apud BORTONI-RICARDO, 2008, p. 34). Assim, a natureza desse tipo de pesquisa é procurar entender, compreender e interpretar fenômenos sociais inseridos em um contexto (cf. BORTONI-RICARDO, 2008).

A pesquisa relatada aqui teve por objetivo realizar um estudo com dez estudantes e profissionais chineses de diversas áreas acerca do status da língua inglesa como língua franca. Respostas desses sujeitos a um questionário (cf. apêndice) com perguntas abertas constituem os dados a serem analisados para que o objetivo proposto seja atingido ${ }^{10}$. O questionário com perguntas abertas foi o instrumento escolhido por possibilitar aos entrevistados escrever respostas livres fazendo uso de suas próprias palavras, evitando limitações e respostas préestabelecidas (COHEN; MANION; MORRISON, 2000).

Os dez chineses foram escolhidos aleatoriamente e possuem idades entre 25 e 28 anos. Cinco dos entrevistados moram na cidade de Wenzhou, dois na cidade de Shangai, e o restante nas seguintes cidades: Ningbo, Pequim e Hangzhou. Wenzhou, Shangai, Ningbo e Hangzhou ficam na parte sudeste da China e Pequim, a capital do país, fica na parte norte.

\footnotetext{
${ }^{10}$ Para realizar esta coleta de dados, enviamos um e-mail a uma chinesa conhecida de uma das autoras deste artigo. Tal chinesa colaborou com a pesquisa, enviando o questionário a alguns de seus conhecidos chineses.
} 
Os dez sujeitos entrevistados exercem as seguintes funções: quatro deles são vendedores, dois trabalham na área de marketing, dois são professores, um estudante e o outro trabalha com negócios internacionais.

Quanto ao curso universitário, temos o seguinte: cinco com graduação na área de línguas estrangeiras (sendo que quatro especificamente na área de inglês), dois com graduação em Economia, dois em Comércio Exterior e um em Administração.

Com relação ao tempo de estudo da língua inglesa, os sujeitos informaram o período de 5 a 15 anos. No que diz respeito ao lugar em que a aprenderam, todos afirmaram ter aprendido na escola, com exceção de um que mencionou ter aprendido a língua sozinho em casa.

\subsection{Descrição e análise dos dados - questionário chineses}

No que se refere à questão número um, a qual pergunta sobre a importância de se aprender a língua inglesa, os chineses entrevistados são unânimes em considerar tal importância. Quando questionados sobre o porquê dessa importância, eles apontaram, em suas respostas, os seguintes motivos: a) é uma língua internacional na situação da economia global; b) o inglês é uma ferramenta para negócios com países estrangeiros:

"The world is a village now, for all trades with foreign countries, English is a must-tool";

c) é a língua mais usada no mundo; d) é uma ferramenta básica na comunicação mundial; e) é um requisito obrigatório para ingressar na universidade e uma vantagem para se conseguir um bom emprego; f) é a disciplina ou o curso principal nas escolas ou universidades; g) é uma língua popular na China:

"English is popular in China, everybody learn it, (......) and all the examinations need to test English”.

Ainda na primeira questão, a língua inglesa representa para os entrevistados o seguinte: a) uma segunda língua, sendo uma maneira de se comunicar com o mundo (respondida por 4 pessoas); b) um modo de conhecimento da cultura de outros países; c) uma língua cada vez mais popular:

"For Chinese now, English becomes more and more popular, from kids to old people, they are willing to learn cause they find the importance of it";

d) representa uma "ferramenta"; e) um entendimento melhor da cultura dos chineses pelos estrangeiros e aprendizagem, por parte dos chineses, sobre os países desenvolvidos: 
"English represents for making foreigner understand our country and cultures and if chances come, we will try to learn more from other developed countries, such as technology, education etc.;

f) a cultura ocidental; g) uma habilidade linguística extra.

Em relação à segunda questão, quando questionados sobre a variedade do inglês mais privilegiada em suas aulas, obtivemos o seguinte dado: apenas um dos entrevistados entendeu realmente essa pergunta, ou seja, compreendeu o que as pesquisadoras indagaram quando questionados sobre a "variedade" do inglês. Para esse entrevistado, então, a variedade mais privilegiada é a americana. Os outros sujeitos nos forneceram dados sobre a habilidade linguística mais enfatizada em suas aulas, as quais foram: compreensão auditiva e oralidade; as quatro habilidades linguísticas; inglês para negócios internacionais, com foco na oralidade; inglês para negócios.

O dado apresentado acima nos leva a pensar que o fato de os entrevistados não responderem qual a variedade do inglês que é ensinada em suas aulas de inglês mostra que ainda não há uma consciência ou uma atribuição de valor sobre tal assunto no contexto pesquisado.

Sobre a terceira pergunta, referente à preferência por falantes nativos ou não-nativos, observamos o seguinte: $80 \%$ dos chineses entrevistados preferem ter aula com falantes nativos; $10 \%$ com não-nativos e os outros $10 \%$ com ambos. Quando indagados o porquê, eles responderam o seguinte:

1) para aqueles que preferem aula com falantes nativos, temos as seguintes justificativas: a) aprendem o inglês "puro" / real; b) conseguem aproveitar mais da comunicação; c) é uma boa maneira de testar o nível da habilidade oral em inglês e eles conseguem obter mais informações com o nativo sobre a cultura:

"It is a good way for us to test the level of our oral English ability (......) we can get more information from the native speaker about the culture";

d) pode melhorar o inglês do entrevistado rapidamente; e) a pronúncia é mais correta e natural; f) conseguem entender melhor sobre a "mente" do inglês;

2) para aqueles que preferem aula com falantes não-nativos, temos o seguinte motivo: a possibilidade de aprendizagem um com o outro, devido às diferentes experiências;

3) para aqueles que preferem ambos: a preferência ao nativo se deve ao fato de eles aprenderem o inglês padrão; e ao não-nativo por ser mais fácil a aprendizagem. 
Em relação ao quarto questionamento, sobre como é o ensino da cultura; e qual cultura é a mais privilegiada em sala, os chineses responderam apenas qual cultura é a mais enfatizada / abordada em suas aulas de inglês, as quais foram: a cultura chinesa ( 2 pessoas) e a cultura de diferentes países ( 3 pessoas) foram a que tiveram mais respostas; as outras, com apenas uma menção, foram as seguintes: cultura chinesa, americana e britânica; cultura americana e britânica, comparadas com as diferenças da cultura chinesa; e cultura de países que falam inglês. Um sujeito salientou que o ensino de cultura não é privilegiado, e outro apenas nos forneceu a sua opinião sobre ensino de cultura: para ele, algumas vezes é desmotivante, outras vezes interessante.

A pergunta número cinco questionava se o ensino do inglês na China considera a língua inglesa como uma língua franca. Todos os sujeitos, com exceção de um, disseram que sim. Dentre as razões para esse fato, foram mencionadas: a) por se aprender / abordar a cultura de diferentes países; b) por ser mais usada para negócios internacionais; c) por ser uma exigência para ingressar na universidade; d) por ser uma língua exigida da educação infantil à universidade (conforme respondido por três sujeitos); e) pelo fato de as escolas enfatizarem mais o uso da língua, especialmente na comunicação. Outro sujeito também afirma que sim, mas não sabe o porquê.

A razão para essa língua não ser considerada franca, de acordo com um dos entrevistados, é que o único objetivo da sua aprendizagem é passar em testes e exames.

Em relação à última pergunta, sobre como deveria ser o ensino da língua inglesa, se a considerarmos uma língua franca, os seguintes aspectos foram levantados: a) ter acesso a notícias e informações de diferentes países; b) considerar a importância da habilidade oral/ foco na comunicação (de acordo com a opinião de dois sujeitos); c) através da prática da língua (respondida por dois participantes); d) tornar a aprendizagem da língua "viva"; e) estimular o interesse dos alunos pela aprendizagem; f) criar mais ambientes para se falar inglês (English talking places).

\subsection{Análise dos dados referentes ao questionário dos chineses}

De uma maneira geral, as respostas aos questionários levam a concluir que a língua inglesa é uma língua popular na China e está presente em todos os níveis do sistema educacional, ou seja, da educação infantil à universidade. 
Notamos, também, que os chineses entrevistados unanimemente acreditam que é importante aprender essa língua. Quando questionados sobre o porquê, vimos que eles não associaram o uso da língua inglesa apenas para se comunicarem /entrarem em contato com países do círculo interno. Pelo contrário, percebemos que a concepção que esses sujeitos têm sobre a língua inglesa refere-se ao seu uso com pessoas de diferentes nacionalidades. Essa constatação pode ser observada através de uma grande ênfase nas palavras "global"; "mundo"; "países estrangeiros"; “comunicação mundial”. Desse modo, evidenciamos que, mesmo ainda não questionados sobre língua franca, os chineses consideram a língua inglesa um meio para se comunicarem com pessoas de países diferentes, e não necessariamente com aquelas que têm o inglês como primeira língua. Essa visão vem ao encontro da definição formulada por alguns autores sobre o que vem a ser uma língua franca: uma língua que possibilita a comunicação de diferentes pessoas que não compartilham da mesma língua materna.

Com relação aos fins ou objetivos de se aprender essa língua, observamos que a maioria dos chineses entrevistados apontou o seu uso para fins pragmáticos ou específicos da língua, tais como usar a língua para negócios internacionais; considerá-la uma "ferramenta"; usar a língua para os estrangeiros conhecerem a cultura deles; foco comunicação/oralidade (usar a língua inglesa para produção). No entanto, saber se eles de fato compartilham desses fins ou se simplesmente estão reproduzindo o discurso vigente seria foco para outra pesquisa.

Sobre os aspectos evidenciados acima, retomamos aqui as considerações feitas por Leffa (2002) quanto ao ensino dessa língua como multinacional ou franca. Duas das implicações salientadas por esse teórico são observadas nas falas dos chineses pesquisados: a) usar o inglês para produção, ou seja, eles não usam a língua apenas para importar informações, mas também para exportá-las, fazendo uso da língua inglesa para que outras pessoas possam conhecer a cultura chinesa; b) usar a língua para propósitos específicos, ou seja, usá-la com propósitos profissionais ou acadêmicos.

Com relação à cultura predominante nas aulas de língua inglesa, detectamos que há um número significativo de respostas que aponta para a cultura de diferentes países, isto é, usar a língua inglesa para conhecer não apenas a cultura dos países do círculo interno, mas usar essa língua para entendimento de outras culturas. Observamos esse dado não somente no item que foi questionado a esse respeito, mas também em outros: se a China considera o ensino da língua inglesa como língua franca (por abordar a cultura de diferentes países) e 
como deveria ser o ensino da língua franca (ter acesso a notícias e informações de diferentes países).

Mesmo com esses indícios de que os chineses consideram a língua inglesa como língua franca (usada por falantes não-nativos; para fins pragmáticos ou específicos; não privilegiar a cultura do nativo), eles têm ainda uma forte preferência pelo falante nativo como professor. O nativo, para eles, é visto como o certo, o padrão, a fonte de informação sobre a cultura ou "mente" nativa. Nesse quesito, ainda vimos certa centralização do falante nativo como um modelo ou padrão a ser seguido. Nessa parte, os chineses entrevistados não fazem nenhuma consideração sobre a importância de se garantir a inteligibilidade entre os falantes, mas apontam quase que em sua maioria para a importância de se ter como modelo o nativo, garantindo assim, a aprendizagem do inglês correto, padrão.

Diante disso, verificamos, de um lado, objetivos de ensino de acordo com aqueles definidos para o ensino de língua franca; referência ao uso da língua para comunicação mundial; não ênfase apenas na cultura dos países do círculo interno em suas aulas; e de outro lado temos: uma preferência quase unânime pelo nativo ou em conhecer a mente nativa e aprender o inglês correto. Nesse sentido, questionamos, qual é o inglês correto, apenas o do nativo? Por que essa preferência tão grande pelo falante nativo?

Uma possível resposta para tal questionamento seria o fato de verificarmos no discurso dos entrevistados um reflexo de décadas de submissão ao imperialismo, sendo que a discussão atual sobre o falante nativo ou qual o padrão a ser seguido ainda não ter chegado de maneira significativa aos aprendizes da língua.

Por fim, notamos que as políticas governamentais de incentivo da língua no contexto chinês são muito presentes e ativas. Essa constatação é evidente quando observamos, como evidenciado anteriormente, as preparações para as Olimpíadas. No contexto chinês, o governo se responsabilizou pela capacitação e incentivo da aprendizagem por pessoas das diversas camadas da sociedade. Uma possível explicação para este fato seria o regime de governo existente nesse país. Na China, como observado no referencial teórico, o regime governamental é mais autoritário e centralizado, não abrindo talvez espaço para iniciativas particulares maiores.

\section{Considerações Finais}


Neste artigo, procuramos investigar as percepções de dez profissionais e estudantes chineses de diferentes áreas do mercado sobre o status da língua inglesa como língua franca. Os resultados apontaram que os sujeitos entrevistados apresentam uma visão bastante próxima daquela que estudiosos e pesquisadores evidenciam sobre o status dessa língua como língua franca: a) a relevância da aprendizagem da língua para propósitos específicos (para o mercado de trabalho, para negócios internacionais, para viagens ao exterior, para comunicação com o mundo e para vida acadêmica); b) a ênfase na prática da língua, para que consigam utilizá-la em situações significativas ou reais; c) a valorização da cultura do próprio país e de outros países e não só daqueles que possuem a língua inglesa como primeira língua; d) o uso da língua para a comunicação com pessoas de diversos lugares do mundo e não somente nativos.

No entanto, observamos que, diferentemente da opinião de estudiosos e pesquisadores sobre o tema, os chineses entrevistados têm uma maior preferência pelo falante nativo como professor, considerando este como o modelo correto e adequado da língua.

De uma maneira geral, cremos que este estudo contribuiu para que olhássemos para outros profissionais (não somente aqueles envolvidos com o ensino de línguas, como estamos mais acostumados a vislumbrar) e analisássemos suas concepções sobre o status da língua inglesa como língua franca. De uma maneira mais específica, os resultados contribuem para conhecermos um pouco mais a realidade de um determinado povo, em época de globalização.

Por fim, ressaltamos que a pesquisa realizada apresenta algumas limitações, já que ela não abrangeu um grande número de pessoas, mas uma parcela muito pequena da população, ou seja, tivemos apenas uma amostragem de como os profissionais e estudantes chineses de diversas áreas do mercado de trabalho estão se posicionando frente à nova realidade linguística que envolve a língua inglesa, como língua franca.

\section{Referências bibliográficas}

BORTONI-RICARDO, S. M. O professor pesquisador: introdução à pesquisa qualitativa. São Paulo: Parábola, 2008.

CHINA massifica ensino de inglês para ingressar na era da globalização. Portal Farol do Brasil, 2007. Disponível em: http://www.revistafator.com.br/ver_noticia.php?not=14505. Acesso em: 01 abr. 2009.

COHEN, L., MANION, L.; MORRISON, K. Research Methods in Education. 5. ed. London: Routledge, 2000. 
COWAN, J. et al. English teaching in China: a recent survey. TESOL Quarterly, v.13, n. 4, p. 465-482, 1979.

FONG, E. T. Y. English in China: some thoughts after the Beijing Olympics. English Today 97, v. 25, n. 1, p. 44-49, mar. 2009.

GIMENEZ, T. Eles comem cornflakes, nós comemos pão com manteiga: espaços para reflexão sobre cultura na aula de língua estrangeira. In: EPLE - Encontro de Professores de Línguas Estrangeira, 9., 2002, Londrina. Anais... Londrina: Apliepar, 2002. p. 107-114.

Antes de babel: inglês como língua franca global. 2009. No prelo.

HE, A. E. Learning and teaching English in the people's republic of China. In: BRAINE, G. (Ed.). Teaching English to the world: history, curriculum and practice. London, 2005. p.1121.

JENKINS, J. The phonology of English as an international language. Oxford, England: Oxford University Press, 2000.

. Current perspective on teaching world Englishes and English as a lingua franca. TESOL Quarterly, v. 40, n.1, p. 157-181, mar. 2006.

KACHRU, B.; KACHRU, Y.; NELSON, C. The handbook of world Englishes. 2006. Disponível em: <books.google.com.br/books?isbn=140511852>. Acesso em: 21 jul. 2009.

LEFFA, V. J. Teaching English as a multinational language. The Linguistic Association of Korea Journal, Seul, Coréia, v. 10, n. 1, p. 29-53, 2002.

McKAY, S. L. Toward an appropriate EIL pedagogy: re-examining common ELT assumptions. International Journal of Applied Linguistics, v. 13, n.1, p. 1-19, 2003.

OYAMA, T. Vocês não entendem a China. Veja, São Paulo, v. 42, n. 29, p. 17-21, jul. 2009.

PHILLIPSON, R. Lingua franca or lingua frankensteinia: English in an European integration and globalization. World Englishes, v. 27, p. 250-267, May 2008.

PENNYCOOK, A. The cultural politics of English as an international language. London: Longman, 1994.

PRICE, R. English teaching in China: changes in teaching methods from 1960-66. English Language Teaching Journal, Oxford, v. 26, n. 1, p. 71-83, 1971.

SEIDLHOFER, B. Closing a conceptual gap: the case for a description of english as a lingua franca. International Journal of Applied Linguistics, v. 11, n. 2, p. 133-153, 2001.

Current perspectives on teaching world englishes and english as a lingua franca. TESOL Quarterly, Columbia, v. 40, n. 1, p. 157-181, 2006.

VANCE, Robert. Why learning English in China is no longer just important. Disponível em: $<$ http://www.teachabroadchina.com/why-learning-english-in-china-is-no-longer-just-

important>. Acesso em: 1 abr. 2009. 


\section{APÊNDICE}

Questionário aplicado a estudantes e profissionais chineses sobre o status da língua inglesa como língua franca.

1) Os chineses acreditam que é importante aprender a língua inglesa? Por quê? O que essa língua representa para vocês?

2) Qual variedade de inglês é / foi a mais privilegiada em suas aulas?

3) Você prefere estudar inglês com um falante nativo ou não-nativo de língua inglesa? Por quê?

4) Como é o ensino da cultura nas suas aulas de inglês? Privilegia-se mais a cultura dos países que falam a língua inglesa, a cultura dos chineses ou a cultura de diferentes países?

5) Você acredita que o ensino do inglês em seu país considera a língua inglesa como uma língua internacional? Se sim, de que maneira?

6) Em sua opinião, como deveria ser o ensino do inglês como língua internacional? 